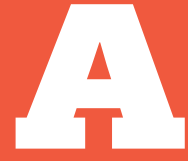

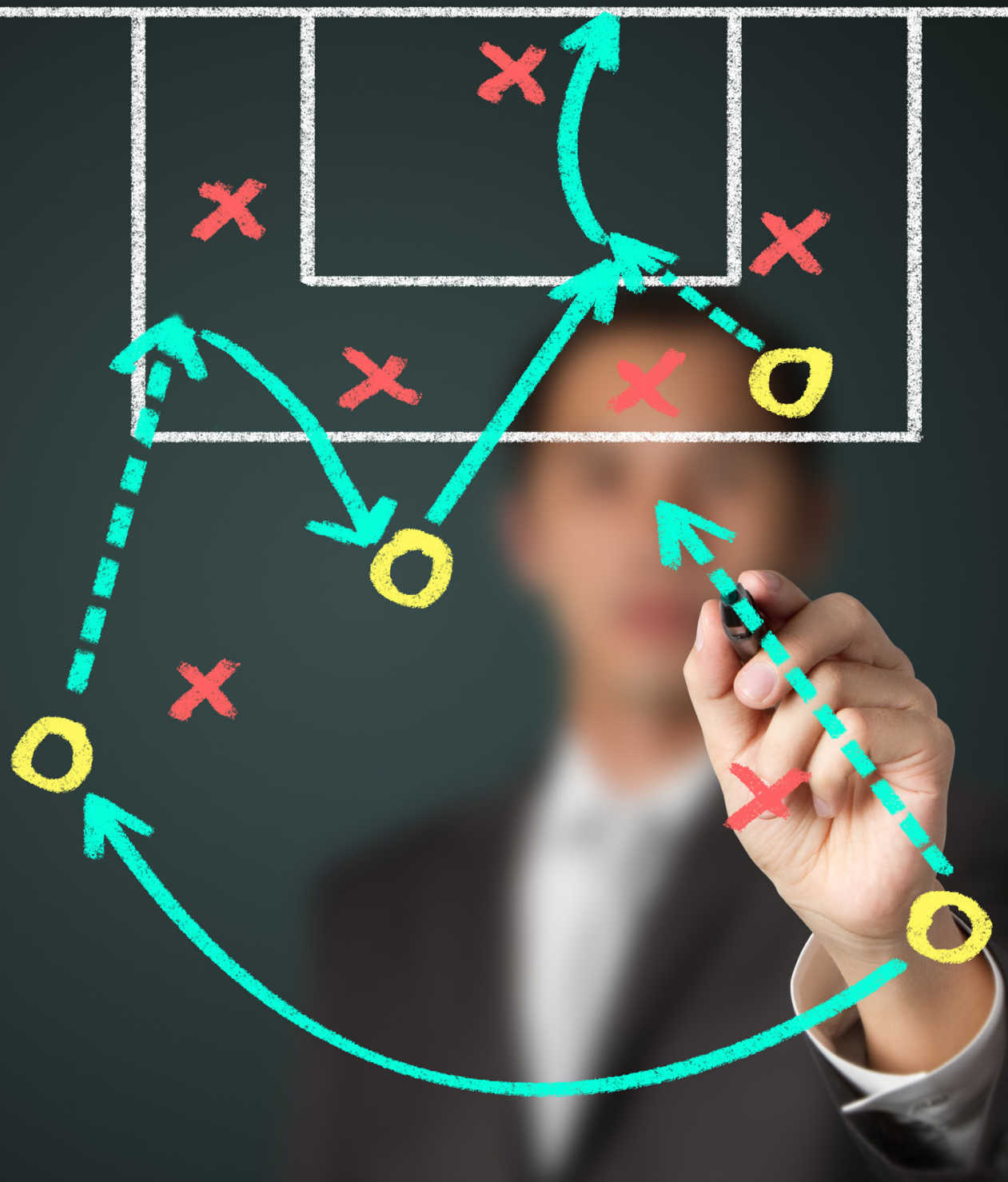




\title{
COACHING: MODO DE USAR
}

\author{
RELATIVAMENTE RECENTE NAS ORGANIZAÇÕES, O COACHING É UMA \\ FERRAMENTA DE DESENVOLVIMENTO PROFISSIONAL E PESSOAL \\ QUE SERVE, EM ÚLTIMA INSTÂNCIA, PARA NOS TORNAR \\ VERSÕES UM POUCO MELHORES DE NÓS MESMOS
}

\author{
| POR ANA LUISA VIEIRA PLIOPAS
}

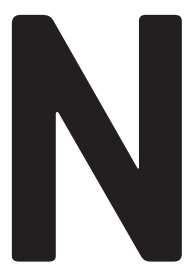

os últimos anos, o termo coaching vem se incorporando rapidamente ao vocabulário e ao dia-a-dia das organizações. Mas por se tratar de uma prática ainda recente, que surgiu na década de 1990, há uma certa confusão a respeito do conceito. Por ser fundamentada em diferentes áreas do conhecimento - como Psicologia e Filosofia - e influenciada por diferentes práticas da Administração, da cultura organizacional e até mesmo dos esportes, a atividade pode deixar a dúvida: afinal, o que é coaching e para que serve?

\section{SOB MEDIDA}

Coaching é um processo de desenvolvimento individualizado, feito sob medida para uma pessoa específica. O exemplo fictício de Jaime, um supervisor recém-promovido a gerente, pode nos ajudar a entender melhor essa definição. Nosso personagem exerceu a atividade de supervisor de projetos de tecnologia por três anos com muito sucesso, principalmente pelo rigor com que cumpria o cronograma e por ser assertivo em suas argumentações em reuniões. Sob sua supervisão, os projetos sempre andavam. O bom desempenho levou à sua promoção como gerente de desenvolvimento, com equipe de 20 subordinados, e foi aí que os problemas começaram. A maneira assertiva e rigorosa de lidar com pessoas, que antes era uma vantagem, agora começou a provocar insatisfação na equipe e aumento do turnover. Foi neste momento que a empresa decidiu contratar um coach.

Mas o que exatamente esse coach faz? Mesmo sendo um processo individualizado, a atividade de coaching segue, em geral, algumas etapas, mostradas na figura abaixo.

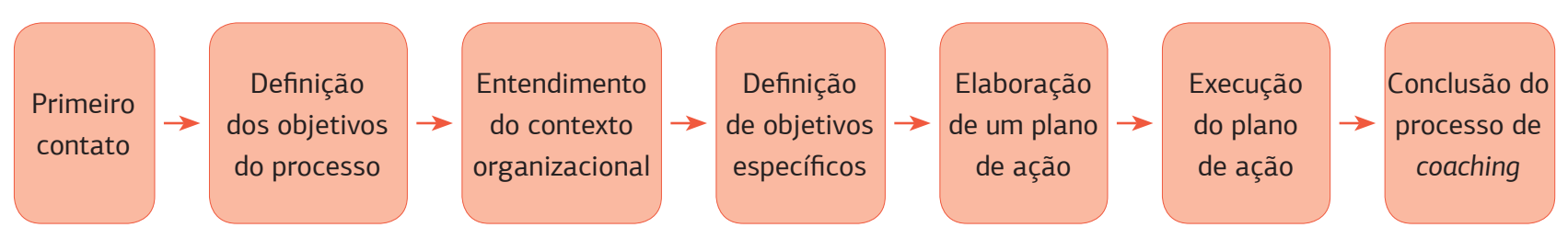




\section{O COACHING OFERECE CONDIÇÕES PARA QUE O PROFISSIONAL SE CONSCIENTIZE DE SI MESMO E DO IMPACTO QUE TEM SOBRE OUTRAS PESSOAS}

\section{PRIMEIRO CONTATO}

Sessões de coaching são conversas em que o coach dá condições para que seu cliente se conscientize de si mesmo e do impacto que tem sobre outras pessoas. Elas também permitem que o cliente examine as suas possibilidades diante de uma situação e só são produtivas se for estabelecida uma relação de confiança entre o cliente e o coach. $\mathrm{O}$ primeiro contato serve para que ambos avaliem se tal relacionamento poderá ser construído.

No caso de Jaime, três coaches diferentes the foram apresentados pela área de Recursos Humanos da empresa. Ele, então, escolheu aquele com quem se sentiu mais à vontade e que the fez sentir mais segurança de que atingiria os resultados desejados.

\section{DEFINIÇÃO DE OBJETIVOS}

Um dos pilares fundamentais de coaching é o sigilo sobre o que é dito nas sessões. Sem dúvida, isso pode levar a um desconforto da organização, que, ao financiar o processo, quer saber se o desenvolvimento do indivíduo atende às suas necessidades. É importante que o chefe, juntamente a um profissional de Recursos Humanos e o próprio funcionário, esclareça para o coach qual o desenvolvimento esperado. Em geral, isso é feito em uma reunião entre o cliente e seu gestor com a presença de Recursos Humanos, e o coach facilita esta interação.

No caso de Jaime, seu chefe expressou que esperava que sua área atingisse todas as metas de entrega e que o clima entre o colaborador e sua equipe fosse amistoso e positivo. Já o profissional de RH ressaltou a importância de baixar o turnover da área.

\section{ENTENDIMENTO DO CONTEXTO}

Mary Beth O'Neill, renomada autora na área, sugere que no processo de coaching diferentes "sistemas" interagem. O primeiro é o mais íntimo e diz respeito ao próprio cliente: suas motivações, características e objetivos pessoais. Em seguida vem o sistema da organização, dos subordinados do indivíduo, de seus pares e clientes. Finalmente, há o contexto socioeconômico no qual a organização está inserida. Entender como o indivíduo é percebido pelo sistema organizacional é um dos fatores que mais propiciam desenvolvimento ao cliente. Na maior parte das vezes, as pessoas não têm ideia de como seu comportamento afeta os outros. Muitos coaches têm a prática de entrevistar pessoas que interagem com seu cliente, obtendo, assim, acesso a tais percepções.

No nosso exemplo, o coach entendeu que Jaime causava temor a seus subordinados. Parte do medo era reflexo das interações na antiga posição ocupada por ele, e outra parte estava relacionada ao hábito que tinha de interpelar seus subordinados na presença de outras pessoas. Embora os questionamentos fossem objetivos e não tivessem qualquer intenção de repreender, Jaime é um homem grande, de voz grave e imponente, e estas interações eram percebidas por seus subordinados como reprimendas públicas.

\section{OBJETIVOS ESPECÍFICOS}

Esclarecidas as expectativas, e com o conhecimento sobre os impactos que o comportamento do cliente causa nas pessoas com as quais interage, coach e cliente definem, de maneira positiva, onde querem chegar com o processo. Esta é, em geral, a etapa na qual ambos buscam um objetivo inspirador, que mobilize o cliente para a ação. Muitos coaches usam fundamentos de psicologia positiva, cujo precursor é Martin Seligman, para ajudar seus clientes a elaborarem objetivos alinhados com o que de fato os mobiliza, tais como "ter uma empresa que promova o bem-estar das pessoas" ou ainda "liderar uma equipe de alta performance". A ideia é buscar, junto ao cliente, o que o movimenta e evitar criar uma lista burocrática de coisas a fazer.

Durante o processo de coaching, Jaime deixou claro que seu interesse na empresa vai além da tecnologia, que é fascinado pelo negócio e que vê a tecnologia como um meio fundamental para a companhia crescer e inovar. Assim, seu objetivo passou a ser transmitir e exercitar tal visão nas interações com sua equipe - sem dúvida, um avanço em relação ao intuito inicial de ser um chefe amistoso e simpático.

\section{PLANO DE AÇÃO}

Definido um objetivo que mobilize o cliente, passa-se então à construção de um plano de ação. Nesta etapa, debatem-se possibilidades e obstáculos, apontam-se riscos e identificam-se caminhos alternativos. Se na etapa anterior o objetivo era buscar o combustível para a ação, nesta fase é construir o caminho que leva o cliente a seus objetivos. 


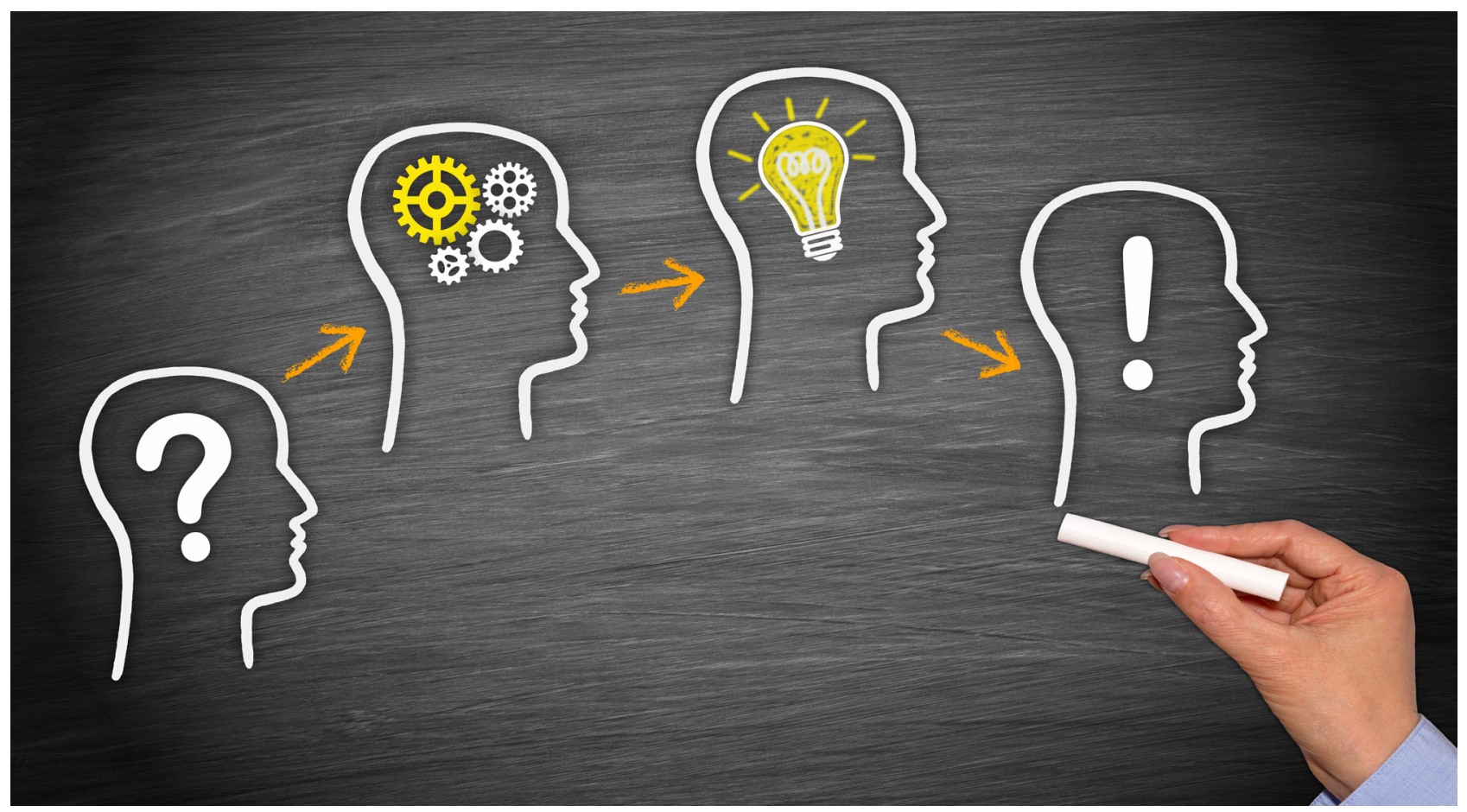

Jaime queria delegar mais e identificar um sucessor. No processo de coaching, ele notou que, em geral, era ele quem falava a maior parte do tempo nas reuniões com sua equipe, e se conscientizou de que o comportamento de "tomar conta da casa" dava pouco espaço para seus subordinados se desenvolverem.

\section{EXECUÇÃO DO PLANO}

Nesta etapa, cliente e coach caminham lado a lado lidando com as resistências que surgem no processo de desenvolvimento. Se as ações a serem tomadas são tidas como ambiciosas demais, são sugeridos passos menores; se o cliente insiste que o mundo não colabora, o coach o desafia e juntos buscam o que pode ser feito no atual contexto. Não é raro que, após o cliente dar seus primeiros passos, novos objetivos sejam traçados e o plano de ação ajustado. O coaching é dinâmico e vai se adequando a novas camadas de complexidade reveladas ao longo do processo.

Aproximadamente no meio do processo de coaching de Jaime, uma nova reunião foi conduzida com seu chefe e o representante de RH. Nessa ocasião, o gestor relatou as mudanças que havia observado no comportamento do colaborador, que, por sua vez, esclareceu quais haviam sido suas intenções. A reunião permitiu ao coach e ao cliente realizarem ajustes no processo. Também fez com que o chefe de Jaime e o profissional de RH continuassem o apoiando em seu desenvolvimento.

\section{CONCLUSÃO DO PROCESSO}

Depois de aproximadamente quinze sessões - que geralmente duram entre uma hora e noventa minutos e ocorrem quinzenalmente -, o coaching costuma chegar ao fim. O término do processo conta com a avaliação das conquistas do cliente e deixa a porta aberta para contatos futuros, já que, se for bem sucedido, estabelece uma sólida conexão entre funcionário e coach. É muito comum que clientes busquem o coach para contar sobre suas conquistas mesmo depois que o processo tenha terminado.

Ao avaliar o coaching, Jaime contou que sua esposa havia notado uma mudança: ele parecia mais paciente e a escutava melhor. De fato, é impossível separar a vida profissional da pessoal e as mudanças de comportamento dos clientes são percebidas por várias pessoas. São alterações pequenas, mas que, como afirma Pamela McLean, pesquisadora e um dos nomes mais importantes na área, permitem que nos tornemos versões um pouco melhores de nós mesmos.

ANA LUISA VIEIRA PLIOPAS > Professora da FGV-EAESP > ana.pliopas@fgv.br 